\title{
In-situ Production Analysis of Composite Precast Concrete Members of Green Frame
}

\author{
Lim, Chae-Yeon ${ }^{1} \quad$ Joo, Jin-Kyu ${ }^{2} \quad$ Lee, Goon-Jae ${ }^{1} \quad$ Kim, Sun-Kuk ${ }^{1 *}$ \\ Department of Architectural Engineering, Kyung Hee University, 1 Seocheon-dong, Giheung-gu, Yongin-si, \\ Gyeonggi-do, 446-701, Republic of Korea ${ }^{1}$ \\ Shindongah Engineering \& Construction, 69-167 Yongsan-dong, Yongsan-gu, Seoul, 501-830, Republic of Korea ${ }^{2}$
}

\begin{abstract}
Recently, there have been many cases in which the difficulty of repair and replacement of principal elements in the bearing wall structure for apartment buildings, which is a major part of apartment buildings in Korea, has led to the reconstruction of buildings rather than their remodeling. To address this problem, the Korea government now allows a floor area ratio of up to $20 \%$, and has relaxed the building height limits to encourage the use of a rahmen structure instead of a bearing wall structure. However, since reinforced concrete rahmen structures have many problems, including higher floor height and greater construction cost, a great deal of research into rahmen composite precast concrete structures have been conducted. Green Frame, one of the developed prototypes, is expected to provide economic benefits through in-situ production for precast concrete column and beam. For in-situ production of composite precast concrete members, a detailed plan for production, curing, and installation is needed. However, it needs to be confirmed that the space is sufficient to produce the precast concrete members on site before planning those activities. Therefore, this study proposes in-situ production analysis of composite precast concrete members of Green Frame with the evaluation of structural safety and available area on the parking structure. The result of this study shows that the in-situ production of precast concrete members is possible through a case study.
\end{abstract}

Keywords : green frame, precast concrete, apartment buildings, precast concrete members, in-situ production

\section{Introduction}

\subsection{Background and Purpose}

Maintenance and remodeling are difficult for bearing wall type apartment buildings, which represent $50 \%$ of residences in Korea, due to partitioning by the bearing wall[1]. This has frequently led to the unnecessary reconstruction of apartment buildings, which not only wastes expense and labor, but also can result in socially

Received : July 3, 2011

Revision received : August 18, 2011

Accepted : September 7, 2011

* Corresponding author : Kim, Sun-Kuk

[Tel: 82-31-201-3365, E-mail: kimskuk@khu.ac.kr

(c)2011 The Korea Institute of Building Construction, All rights reserved. disruptive events, like a sudden rise of real estate prices[2]. To solve this problem, the government has implemented an incentive system that increases the volume and height limit by $20 \%$ if the apartment applies a rahmen structure, which enables easy remodeling and deformation without structural damage.

However, there are many difficulties involved in changing from a bearing wall structure to a rahmen structure. Compared to a bearing wall structure, an in-situ rahmen structure can implement a long span, and easily obtain quality and workability, but may increase floor height and raise construction cost. In this regard, studies have been conducted on precast concrete (PC) 
rahmen structure methods[3]. However, it is difficult to apply a PC rahmen structure, since additional costs may be incurred, such as indirect cost and expense for the production of $\mathrm{PC}$ members at the plant[4].

Developed on this background, the composite PC rahmen structure, Green Frame, allows the main structural members such as PC column and beam to be produced on the site, resulting in a reduction of $\mathrm{PC}$ member transportation cost and the margin of PC plant (operation cost and profit), making it more economic than the bearing wall structure.

For in-situ production of a composite PC member, a careful plan is required for the production, curing and hoisting of members, but before that, the work environment for production should be obtained and checked. In this regard, this study aims to analyze the in-situ production conditions of Green Frame composite PC members using the upside of the underground structure of apartment houses, focusing on the available production areas and structural safety.

\subsection{Methodology}

This study is restricted to the in-situ production and installation of Green Frame PC columns and $\mathrm{PC}$ beams in an apartment building. The following is the procedure used in this study.

First, the feature of Green Frame is examined, and the procedure of in-situ production is compared with PC production in plant. Second, the procedure for analyzing the in-situ production condition of the Green Frame PC member is prepared, after planning construction management conditions and production equipment in accordance with the method of analyzing the load and area conditions. Third, a case is selected and the conditions analyzed according to the prepared procedure. Fourth, the conditions and review opinions on analysis results of in-situ production conditions are drawn.

\section{Preliminary Research}

\subsection{PC Production Method and Procedure}

Factory production of $\mathrm{PC}$ member is carried out as shown in Figure 1. Assembling the mold is the first step. The mold is generally fabricated in steel, since sufficient durability is required for assembling, dissembling and steam curing that are repeated almost every day. Once the mold is assembled, form oil is applied to help concrete come off easily during the removal of the form. When the application of form oil is complete, arranging the bar is the next step. After arranging the bar in the mold, the concrete shall be placed, and compaction performed with the vibrator. For curing after placement, steam curing generally occurs. Curing occurs for 15-20 hours depending on season and form removal strength. After curing is complete, the PC member shall be removed from the mold and transported to the stock yard. Next, transportation to the site and installation at the site is required[4].

In some processes, in-situ production of a $\mathrm{PC}$ member differs from production in a PC plant. Mold is replaced by form for in-situ production. In addition, reinforcement can be performed together with the assembling of the form. It can be assembled in advance and then transported according to the production plan or the progress of work, or can be assembled on the form. The difference from PC plant production is transportation and stock after form removal, as shown in Figure 1, and installation immediately by crane from the production position without a transportation process. This is the biggest 
difference from production in a plant, and results in a cost reduction.

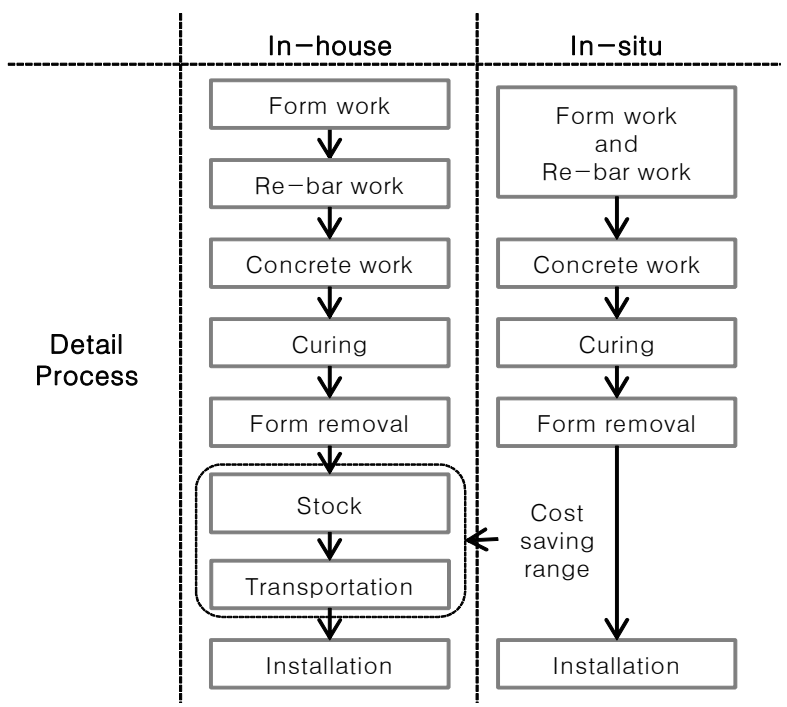

Figure 1. Production process comparison between in house and in-situ production of PC members

\subsection{Green Frame}

Green frame is a composite PC rahmen structure that consists of $450-600 \mathrm{~mm}$ PC column width of 3 floors within 1 member, and PC beam installed for each floor as shown in Figure 2.

For a column with a floor height of $2,900 \mathrm{~mm}$ as shown in the figure, 3 floors of $8,700 \mathrm{~mm}$ become 1 member. PC column and PC beam has the post-and-lintel construction by joint structure so that it can be installed precisely and promptly. After that, the concrete is placed together with slab to secure structural identity. Green frame can improve workability and shorten the construction period through the application of this hybrid connection type.

If the Green Frame is applied to an apartment house, it can maintain the same floor height as the existing bearing wall structure system, along with the variability that the rahmen structure has. In addition, it can reduce the amount of excavation if it is applied to the underground[5].

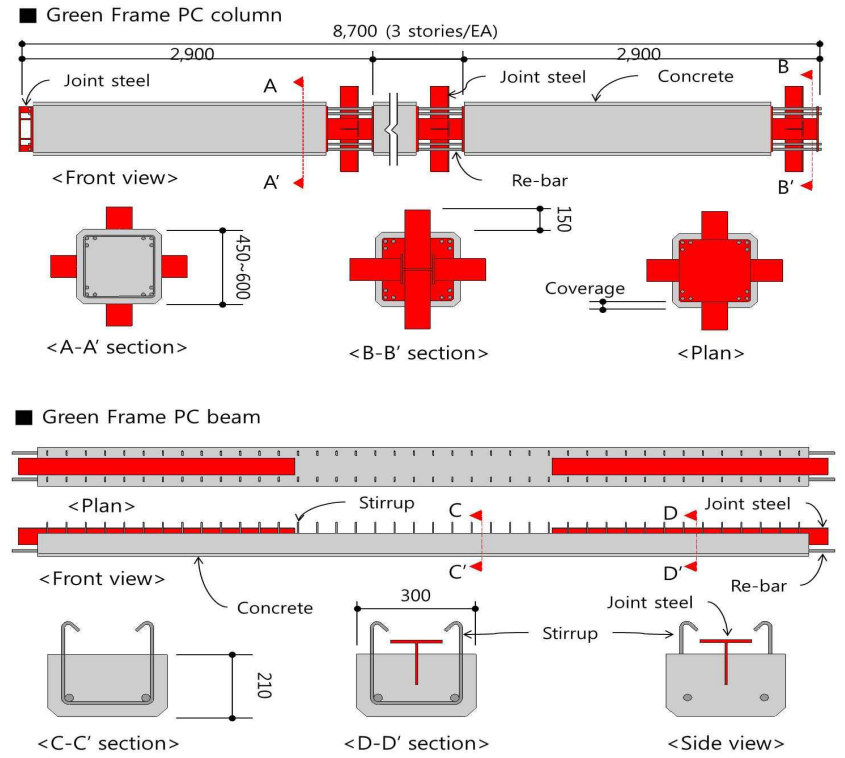

Figure 2. PC column and beam of Green Frame

\section{In-situ Production Analysis}

\subsection{Influence Factors In-situ Production}

If the PC member of Green Frame is produced at the site, the establishment of a detailed plan is important. Influence factors can be largely divided into 8, as shown in Figure 3. These influence factors are correlated, and the possibility of in-situ production can be checked if respective influence factors are mixed and considered in terms of areas and load conditions.

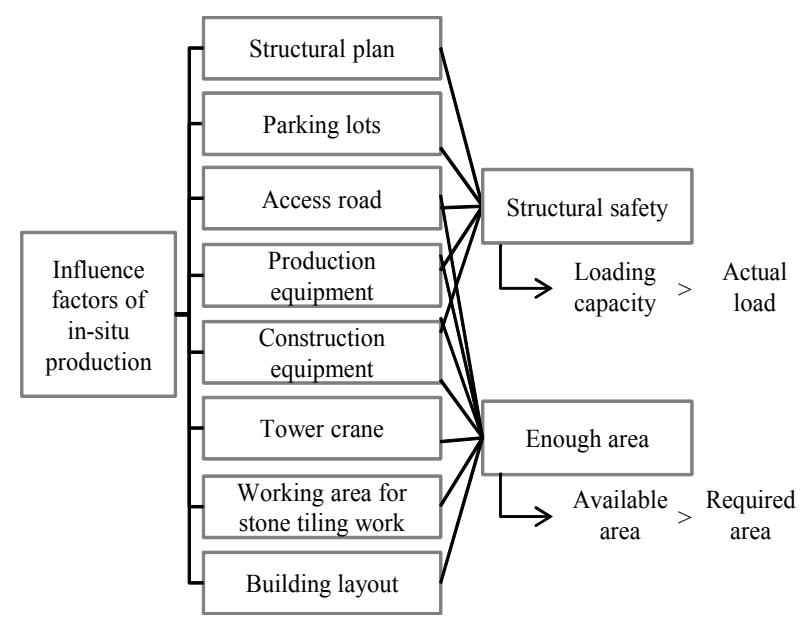

Figure 3. Influence factors of in-situ production 


\subsubsection{Structural Plan}

To plan the in-situ production, the size and quantity of the PC member should be checked first. In addition, the underground structure should be able to support loads such as production equipment, PC member and working load for insitu production. Accordingly, to establish an in-situ production plan, the overall structure plan, including underground structure and apartment building, should be examined.

\subsubsection{Parking Lots}

In-situ production of Green Frame PC member requires the continuous use of equipment such as form and concrete mixer truck until the structural work is finished. If such equipment is arranged on the outside of underground structure, settlement may occur due to longterm load. In addition, since climate change factors such as precipitation may cause problems in the production of the PC member, in-situ production is planned on the upside of the underground structure.

\subsubsection{Access Road}

In general, there is no main access road of construction equipment in the construction site and lots of parts are allocated as passages, resulting in confusion of the movement line and the lack of a work area. However, as a large area is required for the production of the PC member on the site, it is necessary to enhance the space efficiency and prevent confusion of the movement line by regulating the work equipment to pass through the designated passage. In addition, for the transportation of finishing materials and the passage of workers, a sub access road is required from the main access road to the lift car of each building. Such an access road should be considered when establishing a production arrangement plan.

\subsubsection{Production Equipment}

As the forms generally used for the production of PC members in the PC plant are heavy and bulky, and heavy equipment is required when this is applied to PC in-situ production, it can lead not only to safety problem but also increased construction costs in the making of the form. On the other hand, if a plywood form is used for insitu production, it requires lots of manpower and results in low workability, increased construction period and lower quality. In addition, it generates lots of construction waste due to the low conversion of the plywood form.

Accordingly, production of the form in steel is required for the in-situ production of Green Frame, in consideration of workability and economy[6]. The shape of the form for the in-situ production of Green Frame is as shown in Figure 4. The production of 2 columns and 3 beams at a production module is planned. Production module will be explained according to the size of $\mathrm{PC}$ member in Section 3.3.

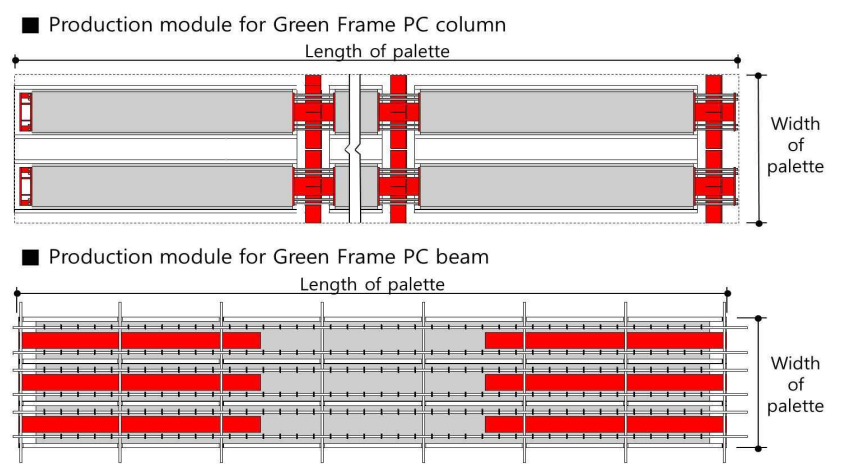

Figure 4. Production module for Green Frame column and beam

\subsubsection{Construction Equipment}

The construction equipment required includes a concrete mixer truck and a 15-ton dump truck. Trucks heavier than this will not be used for ordinary work. Accordingly, if the passage of a 
concrete mixer truck and a 15-ton dump truck is possible on the upside of the underground structure, it also means that it is safe for the passage of other equipment, including a forklift.

The maximum loaded vehicle weight of concrete mixer trucks and dump trucks currently sold on the Korean market was found to be about 26 tons. By examining the full length and full width for load and space review, the heaviest vehicle that can be used is a 15 ton dump truck manufactured by SS company, as shown in Table 1 and Table 2 .

Table 1. Specifications of concrete mixer trucks

\begin{tabular}{ccccc}
\hline Capacity & Manufacturer & $\begin{array}{c}\text { Loaded } \\
\text { weight } \\
\text { (ton) }\end{array}$ & $\begin{array}{c}\text { Length } \\
(\mathrm{m})\end{array}$ & $\begin{array}{c}\text { Width } \\
(\mathrm{m})\end{array}$ \\
\hline $6 \mathrm{~m} 3$ & $\mathrm{D}$ & 26.20 & 8.260 & 2.495 \\
& $\mathrm{H}$ & 26.13 & 8.335 & 2.490 \\
& $\mathrm{~S}$ & 26.30 & 7.950 & 2.490 \\
\hline
\end{tabular}

Table 2. Specifications of dump trucks

\begin{tabular}{ccccc}
\hline Type & Manufacturer & $\begin{array}{c}\text { Loaded } \\
\text { weight } \\
\text { (ton) }\end{array}$ & $\begin{array}{c}\text { Length } \\
(\mathrm{m})\end{array}$ & $\begin{array}{c}\text { Width } \\
(\mathrm{m})\end{array}$ \\
\hline \multirow{4}{*}{15 ton } & H & 25.96 & 7.695 & 2.495 \\
& D & 26.13 & 7.685 & 2.495 \\
& SS & 26.44 & 7.595 & 2.495 \\
& S & 26.24 & 7.445 & 2.495 \\
& K & 26.07 & 7.522 & 2.490 \\
\hline
\end{tabular}

\subsubsection{Tower Crane}

In-situ production of Green Frame PC member occurs within the slewing radius of crane in order to immediately lift at the position of production without stock or horizontal movement after curing of the member. For this purpose, arrange one crane for each building. If it is not possible to arrange all production modules within the slewing radius of crane, modify the location or the capacity of crane.

\subsubsection{Working area for stone tiling work}

Here, working area for stone tiling work refers to the distance outside the apartment building. There is no legal restriction, but a separation distance of $5 \mathrm{~m}$ should be secured in order to obtain the access road for materials, equipment and workers and to prevent safety accidents related to falling objects. Production equipment should not be arranged within the separation distance from the building in order to avoid problems in the execution of works. In addition, this space can be utilized for stone tiling work on the lower part.

\subsubsection{Building Layout}

Arrangement of the apartment building according to the construction plan is related to most of the influence factors described above. It is a very important factor in planning the access road. In addition, it has direct effects on the arrangement of production equipment, as well as the arrangement of the tower crane. In particular, the arrangement of the apartment building and the slewing radius of tower crane should both be considered for the arrangement of production equipment.

\subsection{Planning Process of In-situ Production}

As such influence factors of in-situ production are related to each other, they should be examined in a logical order. In this regard, this study establishes a production plan through assumptions and analyzes the influence factors. The procedure of analysis is as shown in Figure 5. 


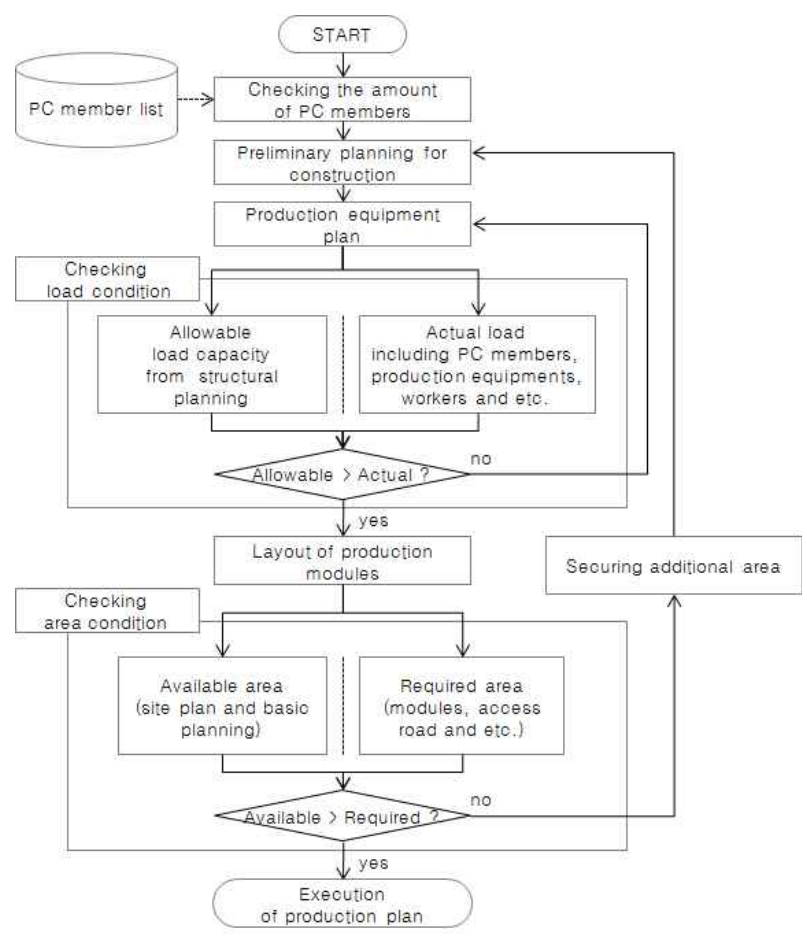

Figure 5. Planning process of in-situ production

1) Selecting the case project and identifying the required quantity of columns and beams for Green Frame.

2) Establishing the work management plan.

The work management plan includes the arrangement of tower crane, stone tiling work on the lower part of apartment building, separation distance from building for the installation of a safety network, securing of access road, and stock yard of various finishing materials.

3) Establishing a production equipment plan based on the required quantity of $\mathrm{PC}$ member.

The production equipment plan includes a form and curing system for in-situ production, as well as construction equipment such as forklift, concrete mixer truck and dump truck.

4) Examining structural safety in consideration of additional load during the production process and other work management conditions as well as the established equipment plan. If the examination shows that structural safety has not been obtained, establish and examine the production equipment plan again. Obtain structural safety by making a change such as securing space between forms or redesigning the form for in-situ production to make it lighter.

5) Once structural safety is obtained, arrange the production equipment and work equipment on the drawing to examine the areas. If the required space for PC production or required area for the execution of works is not sufficient, the production plan can be changed so that the available areas are more than the required areas.

\subsection{Production Equipment Plan}

The unit production module of a PC column consists of 3 Palettes 1 ) and 12 side forms. The PC column of Green Frame is generally less than $500 \mathrm{~mm}$ in width. Production module produced with a column width of $500 \mathrm{~mm}$ can be universally used for the column below $500 \mathrm{~mm}$ in width. In this case, there is the pallet only on the concrete area due to the projection of joint steel between PC columns, and is designed in the length of $2,600 \mathrm{~mm}$ with a clearance of $30 \mathrm{~mm}$ on both sides to install the joint steel during production. Since such pallets weigh $229.18 \mathrm{~kg}$ each and the side form weighs $44.07 \mathrm{~kg}$, total weight of in-situ production form for columns is 1.22 tons, as shown in Table 3. In a special case, when the cross section width of PC column exceeds $500 \mathrm{~mm}$, the form is separately designed and produced.

Unit production module of PC beam consists of 2 palettes, 2 internal forms and 2 external forms. PC beam of Green Frame does not exceed $6 \mathrm{~m}$ in length in general cases. Design the pallet for the

1) Pallette means the bottom form for production of $\mathrm{PC}$ members. 
production of a PC beam less than $6 \mathrm{~m}$ long in the total of $6,300 \mathrm{~mm}$ by calculating $150 \mathrm{~mm}$ for space on both ends. Since a pallet like this for beam production weighs $500.06 \mathrm{~kg}$, external form, $70.22 \mathrm{~kg}$, and internal form weighs $47.85 \mathrm{~kg}$, the total weight of the in-situ production form for beams is $736.20 \mathrm{~kg}$. Provided, however, that manufacturer and user use separate in-situ productions form in order to fabricate a beam that exceeds $6 \mathrm{~m}$ in length, the same as the column.

Table 3. Specification of in-situ production form

\begin{tabular}{|c|c|c|c|c|c|}
\hline \multirow{2}{*}{ Description } & \multirow{2}{*}{\multicolumn{2}{|c|}{$\begin{array}{c}\text { Size }(\mathrm{mm}) \\
\text { (length } X \text { width } X \text { hight) }\end{array}$}} & \multirow{2}{*}{ No. } & \multicolumn{2}{|c|}{ Weight (kg) } \\
\hline & & & & Unit & Total \\
\hline \multirow{3}{*}{ Column } & Palette & $2,600 \times 1,400 \times 550$ & 3 & 229 & 688 \\
\hline & Side form & $2,600 \times 42 \times 600$ & 12 & 44 & 529 \\
\hline & $\begin{array}{l}\text { A set } \\
\text { of forms }\end{array}$ & $8,760 \times 1,400 \times 655$ & 1 & & 1,216 \\
\hline \multirow{5}{*}{ Beam } & Palette & $6,300 \times 1,222 \times 550$ & 1 & 500 & 500 \\
\hline & $\begin{array}{l}\text { Inner } \\
\text { form }\end{array}$ & $6,300 \times 44 \times 220$ & 2 & 48 & 96 \\
\hline & & & & & \\
\hline & Side form & $6,300 \times 42 \times 220$ & 2 & 70 & 140 \\
\hline & $\begin{array}{l}\text { A set } \\
\text { of forms }\end{array}$ & $6,300 \times 1,222 \times 400$ & 1 & & 736 \\
\hline
\end{tabular}

\subsection{Review of Load Conditions}

Form is installed for the production of the PC column and PC beam of Green Frame, and the access road is on the upside of the underground structure. Accordingly, examine the structural stability of underground structure for weight of forms and construction vehicle passage load, as shown in formula (1).

In general, for the structural standard of an underground structure, it is necessary to compare the DB load due to vehicle passage and the status load with the cover layer, and apply the unfavorable cases between them. Accordingly, it is necessary to examine the structural safety in the unit of parking lot module, examine the uniformly distributed load of the cover layer based on the self load, and examine the concentrated load based on the DB load2) to secure structural safety.

$$
L C>L_{a}---------(1)
$$

where, LC : loading capacity of underground structure

$L_{a}$ : actual load which is loaded on

Such DB load is expressed as DB-13.5, DB-18 and DB-24, and refers to maximum axial loads of 5.4 tons, 5.2 tons and 9.6 tons, respectively[7].

\subsubsection{Load on Parking Lot Module}

The ordinary underground parking lot of an apartment building is designed in modules of 8,250 $\times 8,250 \mathrm{~mm}$ as shown in a) of Figure 6 , and can be designed in modules of $8,250 \times 10,400 \mathrm{~mm}$ b) as shown in Figure 6) if Green Frame is applied. Since load on the upside of the underground structure is delivered on 4 columns, it is necessary to analyze and examine such parking module unit load condition in order from in-situ production plan.

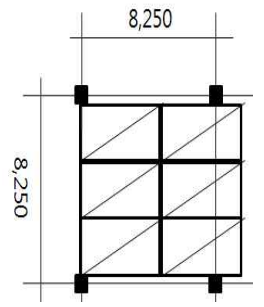

a) Parking module $A$

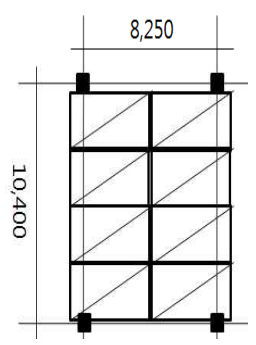

b) Parking module $B$
Figure 6. Parking modules of underground parking lots

2) $\mathrm{DB}$ load refers to the load of the car based on the design introduced in "Steel Plate Design Standard Specification' in 1962 for determination of road structure standard. 
In terms of the method used to examine the actual load, calculate as shown in formula (2) based on the assumption that the load on the upside of the underground structure is big, and follow the method of comparing it with available load as shown in formula (1). Table 4 shows 5 different combinations of the arrangement of the heaviest dump truck(s) among many other different types of construction equipment and the heaviest PC column modules among production modules on a parking module shown in the Figure 6.

$$
T L=1.2 \times D L+1.6 \times L L
$$

Where, $T L=$ total load

$$
\begin{aligned}
& D L=\text { dead load } \\
& L L=\text { live load }
\end{aligned}
$$

Table 4. Arrangement cases for loading conditions

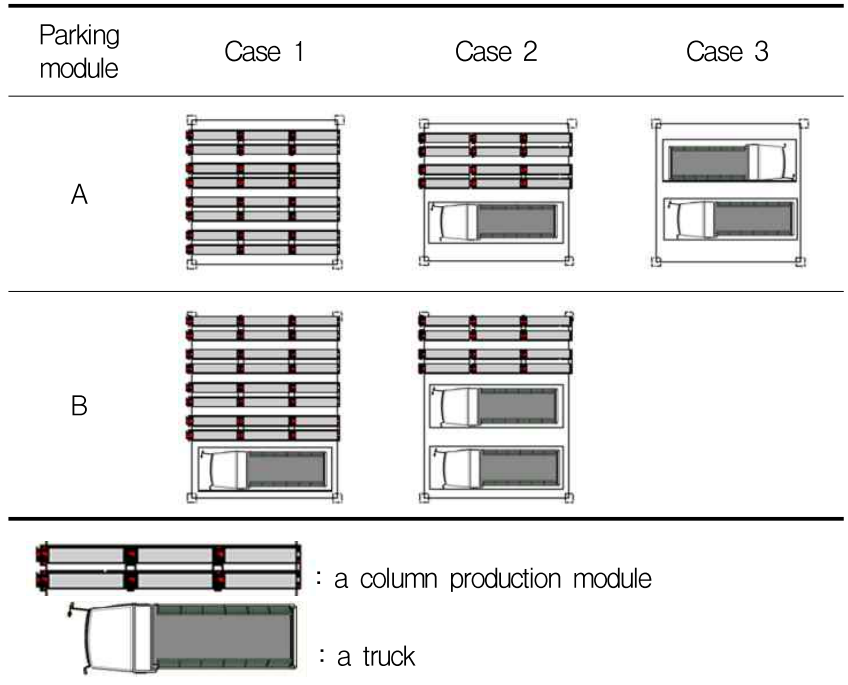

\subsubsection{Uniform Load of In-situ Production Module}

To check load capacity, calculate the load of PC member to be produced and production equipment as a load per unit area, and compare it with the structural plan. Through this, the structural safety for the uniform distributed load of PC in-situ production module can be confirmed.

\subsubsection{Concentrated Load by Operation of Heavy Weight Vehicle}

Calculate the maximum axial load of construction equipment based on DB load, and compare it with the structural plan. A driving vehicle generates other load effects in addition to the load at stop status due to several factors such as speed, weight and vehicle vibration. Since it is difficult to clearly calculate and reflect such load effects theoretically, they are expressed by multiplying static live load (vehicle load) by a certain factor. This is called impact coefficient. Standard specification of Korea Expressway Corporation allows to consider up to 30 $\%$ of static live load as dynamic live load, that is, impact factor (I) as shown in the formula (3)[8].

However, by calculating the load of dump truck of SS company through formula (4) in consideration of impact factor $0.3,34.23$ ton is calculated.

$$
I=\frac{12}{40+L} \leq 0.3
$$

where, $I$ = impact factor

$L=$ length of vehicle

$$
W_{i}=W_{v} \times(I+1)---------(4)
$$

where, $W_{i}=$ weight considering impact factor

$W_{\mathrm{V}}=$ total weight of vehicle

Total weight obtained this way should be converted to axial load to compare with DB load. According to DB load standard, since maximum axial load takes $0.4 \mathrm{w}$ out of total $1.8 \mathrm{w}$ as shown in Figure 7 [7], it can be obtained by dividing the total weight by 1.8 and multiplying it by 0.4 . Maximum axial load of a 15 ton dump truck, calculated with this procedure, is 7.6 tons. Accordingly, the standard of DB-24 should be applied to allow the passage of a 15 ton dump truck heavier than a concrete mixer truck on the upside of underground structure. 
If structural safety is not confirmed through these 3 reviews, it can be solved by redesigning the form for in-situ production to be lighter, or by using lighter construction equipment.

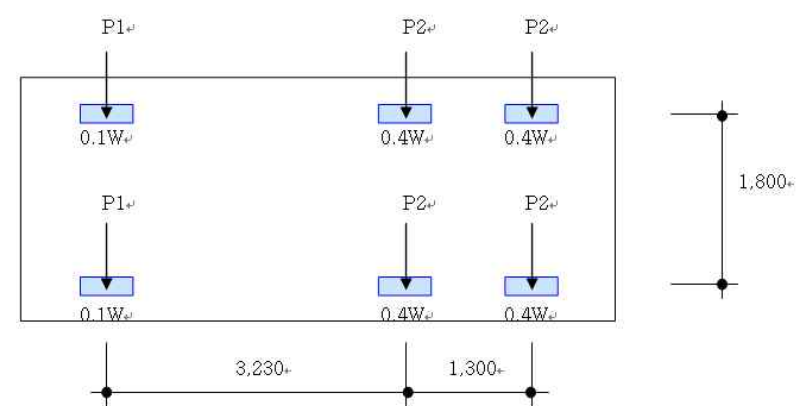

Figure 7. Load ratio of 3 axle vehicles

\subsection{Review of Area Conditions}

Once structural safety is secured, establish a production arrangement plan. The required area for arrangement should be smaller than the available area of the underground structure, as shown in the formula (5). At this time, the available area is the area left after first subtracting the area on which the building is built, the area of the parking ramp, the area required to be distanced from the building, and the access road for the passage of the various equipment from the entire area above the underground parking lot.

$$
A_{a}>A_{r}
$$

where, $A_{a}$ : available area for production

\section{$A_{r}:$ required area for production}

Since such a review of area conditions considers only the required areas for production, the formula (5) is expressed as an inequality. The area required for the stockyard of finishing materials as well as required areas for other work plans are allocated to the space other than the upside of the underground structure, but if necessary, they can be additionally allocated to an area other than the required area for production. If the arranged area is lacking, this problem can be solved by modifying the basic construction plan. At this time, change of the capacity and location of the tower crane, change of the access road as well as production using the underground level can be considered.

\section{Case Study}

\subsection{Selection of Case Project}

The selected case project is an apartment construction site at Gyeonggido. Most ground space was allocated as a green and neighboring living facility space for the purpose of improving the satisfaction of tenants and providing an environmentally-friendly feature. After analyzing the feasibility, a big deficit was expected for the project when the project approval was obtained. For this reason, it was re-designed with Green Frame for the purpose of reducing the apartment price, improving the seismic performance, and enabling the variability of the architectural plan at the request of the project owner.

The case projects designed using the bearing wall structure include 11 buildings with volume of $208.96 \%$ as shown in Table 5. With the application of Green Frame, such case projects were redesigned by relaxing volume to $227.87 \%$ based on the local ordinance. However, since the project is in a height restriction area, the number of floors was lowered and 2 buildings were added, resulting in 13 buildings instead of the previously planned 11 buildings. With this, the building coverage increased from $16.63 \%$ to $18.91 \%$. While recent apartments have lower building coverage and more green space in order to improve the living environment and secure prospect right and right to sunshine at the request of consumers, [6] cases with building coverage of $18.91 \%$, which run counter to this trend, are fairly rare. 
Table 5. Brief description of a case project

\begin{tabular}{ccc}
\hline & \multicolumn{1}{c}{ Before } & \multicolumn{1}{c}{ After } \\
\hline Structure type & Bearing wall & Green Frame \\
Location & O City, Gyeonggi & do \\
Site area $\left(\mathrm{m}^{2}\right)$ & $57,333.00$ & \\
Total floor area $\left(\mathrm{m}^{2}\right)$ & $167,064.13$ & $180,498.52$ \\
Volume $(\%)$ & 208.96 & 227.87 \\
Building area $\left(\mathrm{m}^{2}\right)$ & $9,532.12$ & $10,841.67$ \\
Building coverage $(\%)$ & 16.63 & 18.91 \\
Number of Buildings & 11 & 13 \\
Stories & F27, B2 & F25, B2 \\
\hline
\end{tabular}

\subsection{Production Equipment Plan}

In the selected case, there is no PC column exceeding $500 \mathrm{~mm}$ in width. Accordingly, the size and the weight of the production module are as shown in Table 3 .

Since the heaviest PC column is 5.48 tons and a total of 2 columns are produced from the unit production module, the member weighs 10.96 tons. The highest loads are given on the upside of underground structure when the concrete is placed during PC member production process. At this time, since the form is already installed, assume dead load and consider the PC load as a live load in consideration of the concrete placement load and impact load. In addition, consider the weight of workers and the weight of various members as a live load of $200 \mathrm{~kg}$. Accordingly, since the in-situ production form is dead load as shown in formula (2), calculate it as 1.2 times, and consider live load for the PC members, calculate it as 1.6 times so that the total load of the column production module is 19.66 tons.

In addition, since the heaviest $\mathrm{PC}$ beam is 1.15 tons and a total of 3 beams are produced from the unit production module, the members weigh 3.45 tons. Load of the beam production module is calculated as a total of 6.4 tons in consideration of the safety ratio, using the same method as the column production module.

\subsection{Review of Load Conditions}

According to the structure plan of the selected case, the structure standard of the upper part of underground parking lot is "since the entry of construction equipment is inevitable during construction, compare the cases when uniformly distributed $16 \mathrm{kPa}$ is loaded and the case when $\mathrm{DB}$ 24 movement load is loaded, and apply the unfavorable case." Accordingly, examine the uniform load based on $16 \mathrm{kPa}$, that is, about $1.63 \mathrm{ton} / \mathrm{m}^{2}$, and live load based on $\mathrm{DB}-24$. But, since the standard of DB-24 is applied for the movement load, safety is secured as confirmed in Section 3.3.

\subsubsection{Load on Parking Lot Module}

The parking lot module of the case project consists of 2 types as shown in Figure 6. Loading performance burdened by each module is 111 tons for Parking Module A and 140 tons for B, as shown in Table 6.

If production module and dump truck are arranged to the parking module as shown in Table 4 , the load for all cases is calculated based on the weight of the production module obtained in Section 4.2 and the weight of the dump truck checked in Section 3.1. Load can be obtained as shown in Table 7 by multiplying the weight of the dump truck, 26.44 tons, by 1.6 times in consideration of the movement load and applying the weight of the column production module, 19.66 tons. By comparing this with the loading capacity of each parking module, structural safety was secured for all cases. 
Table 6. Loading capacity of parking structures

\begin{tabular}{ccc}
\hline $\begin{array}{c}\text { Parking } \\
\text { module }\end{array}$ & $\begin{array}{c}\text { Area } \\
\left(\mathrm{m}^{2}\right)\end{array}$ & Loading capacity (ton) \\
\hline A & 68.06 & 111 \\
B & 85.80 & 140 \\
\hline
\end{tabular}

Table 7. Allowable load comparison for each case

\begin{tabular}{|c|c|c|c|c|c|c|c|c|c|}
\hline \multirow[b]{2}{*}{$\begin{array}{l}\text { Parking module } \\
\text { (loading } \\
\text { capacity, ton) }\end{array}$} & \multicolumn{3}{|c|}{ Case 1} & \multicolumn{3}{|c|}{ Case 2} & \multicolumn{3}{|c|}{ Case 3} \\
\hline & $\begin{array}{l}\text { Actual } \\
\text { load } \\
\text { (ton) }\end{array}$ & $\begin{array}{c}\text { Ratio } \\
(\%)\end{array}$ & Safety & $\begin{array}{l}\text { Actual } \\
\text { load } \\
\text { (ton) }\end{array}$ & $\begin{array}{l}\text { Ratio } \\
(\%)\end{array}$ & Safety & $\begin{array}{l}\text { Actual } \\
\text { load } \\
\text { (ton) }\end{array}$ & $\begin{array}{l}\text { Ratio } \\
(\%)\end{array}$ & Safety \\
\hline$\underset{(111)}{A}$ & 79 & 71 & OK & 82 & 74 & OK & 85 & 76 & OK \\
\hline $\begin{array}{c}\text { B } \\
(140)\end{array}$ & 121 & 86 & OK & 124 & 89 & OK & & & \\
\hline
\end{tabular}

Ratio : (actual load) $\div$ (load capacity) X $100 \%$

\subsubsection{Uniform Load of In-situ Production Module}

In accordance with the structural plan, it is safe if the load is less than about $1.63 \mathrm{ton} / \mathrm{m}^{2}$ for a uniformly distributed load. Since the column production module is $1.4 \mathrm{~m}$ wide and $8.7 \mathrm{~m}$ long, it occupies the area of $12.18 \mathrm{~m}^{2}$.

By dividing the load (19.66 tons) of the column production module obtained in Section 4.2 by the area of the unit production module $\left(12.18 \mathrm{~m}^{2}\right)$, it becomes $1.61 \mathrm{ton} / \mathrm{m}^{2}$. Since this value considered the safety ratio and is smaller than the $16 \mathrm{kPa}\left(1.63 \mathrm{ton} / \mathrm{m}^{2}\right)$ indicated in the structural plan, the unit production module of the PC column satisfies the structural standards of the parking lot.

By calculating the load of the PC beam production module by the unit area in the same process as the pillar, $0.73 \mathrm{ton} / \mathrm{m}^{2}$ is obtained. Since this value is smaller than the load by the column production module, the beam production module also satisfies the structural standards of parking lot.

\subsection{Production Module Arrangement Plan}

As structural safety was confirmed, arrange the production module and the access road in the site plan as shown in Figure 8. Since the lifting load increases according to the application of PC method, 1 tower crane for each building as shown in Figure 9 is needed to solve this increase in lifting load and to shorten the construction period.

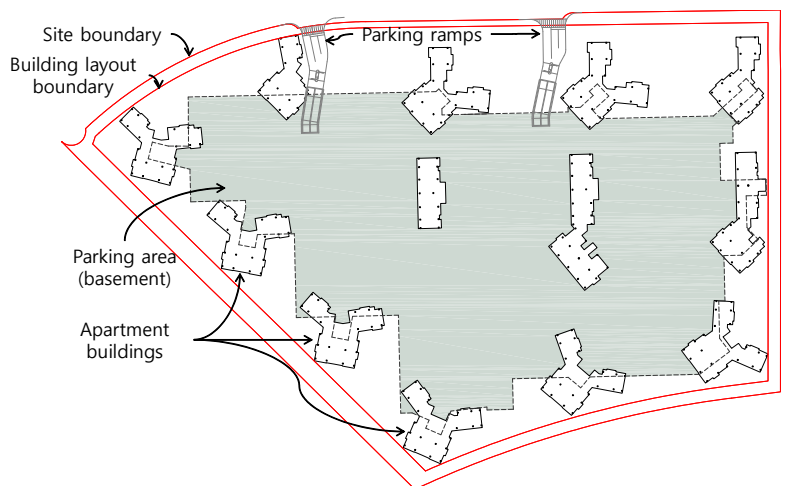

Figure 8. Site plan

After zoning the site based on the shape of the underground structure, the arrangement of the apartment building and the slewing radius of the tower crane, arrangement of the access road shall follow in reference to the boundary of separating the zone. After that, allow $5 \mathrm{~m}$ from the building and indicate the line for safety and various finishing works and stone tiling work on the lower part. Do not arrange PC production equipment in the separation distance from the building and the access road, so that work can be executed smoothly. The results of arranging the separation distance of building and the access road are as shown in Figure 10.

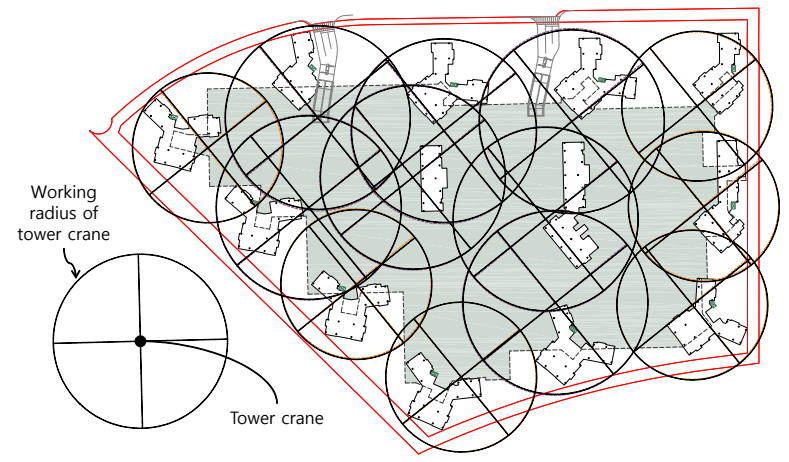

Figure 9. Planning of tower cranes 
After zoning the site based on the shape of the underground structure, the arrangement of the apartment building and the slewing radius of the tower crane, arrangement of the access road shall follow in reference to the boundary of separating the zone. After that, allow $5 \mathrm{~m}$ from the building and indicate the line for safety and various finishing works and stone tiling work on the lower part. Do not arrange PC production equipment in the separation distance from the building and the access road, so that work can be executed smoothly. The results of arranging the separation distance of building and the access road are as shown in Figure 10.

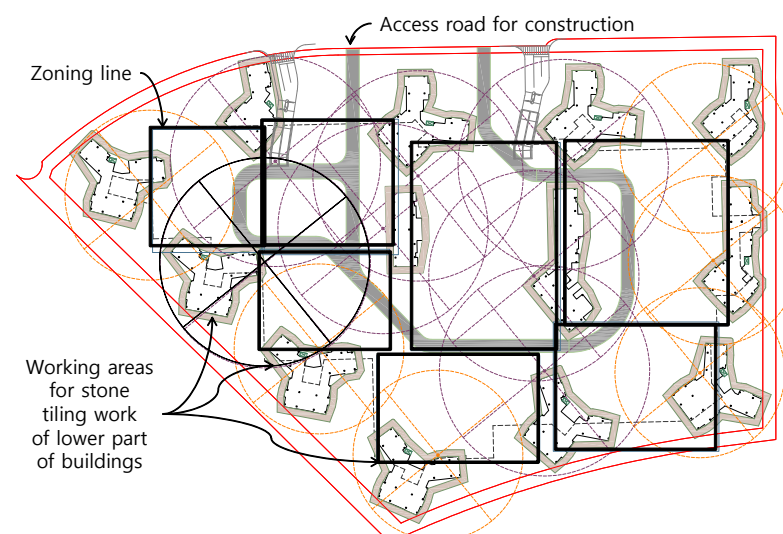

Figure 10. Zoning of access road and production area

When completing the arrangement of the access road, arrange the $\mathrm{PC}$ member production module of Green Frame within the slewing radius of the crane of each building. This is to enable the PC member to be lifted directly from the production position.

For production of $\mathrm{PC}$ member, do not use the pump car but directly place it using the chute of concrete mixer truck to improve quality and productivity, and to reduce construction cost. To achieve this, arrange a $4.5 \mathrm{~m}$ passage between production modules so that a concrete mix truck can freely pass. Arrange such sub access road in a radial shape so that it can be directly connected from the access road. Since a sub access road is an empty space except during concrete placement for PC production, it can be used as a subsidiary passage of equipment transporting miscellaneous materials and finishing. The results of arranging the production module in consideration of such conditions are as shown in Figure 11.

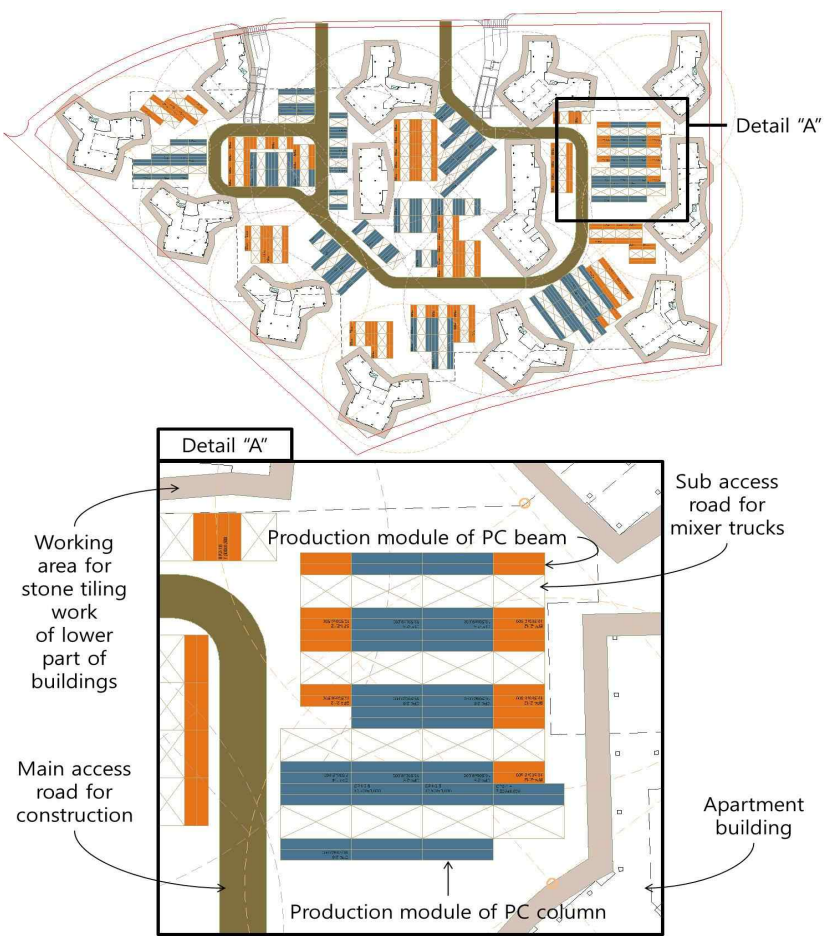

Figure 11. Layout of in-situ production of PC members

\subsection{Review of Area Conditions}

By establishing the production module and arrangement plan, most of the upside area of underground structure is used for production, as shown in Figure 11. To quantify this, compare the available production area and required production area as shown in Formula (5).

First of all, the underground floor area obtained to calculate the available production area is 37,728 $\mathrm{m}^{2}$. By subtracting the building area of $10,841 \mathrm{~m}^{2}$, area of access road of $3,74 \mathrm{~m}^{2}$, area of underground parking lot lamp of $172 \mathrm{~m}^{2}$, and area of stone attachment work on the lower part of 
$3,096 \mathrm{~m}^{2}$ from this value, $19,824 \mathrm{~m}^{2}$ is obtained as the available area for in-situ production, as shown in Table 8.

Then, by analyzing the area of subsidiary passage and PC member in-situ production module arranged as shown in Figure 11, the required production area of $11,146 \mathrm{~m}^{2}$ was calculated. Since it is $56.22 \%$ in comparison with the available production area, Formula (5) is valid. Accordingly, the area for producing the PC member of Green Frame on the site is sufficient, and the remaining area of $43.78 \%$ can be utilized as an additional space for finishing work.

Table 8. Available area for in-situ production

\begin{tabular}{ccc}
\hline Description & Area $\left(\mathrm{m}^{2}\right)$ & Ratio $(\%)$ \\
\hline Parking area & 37,728 & 100.00 \\
Building area & 10,841 & 12.62 \\
Working area for stone tiling work & 3,096 & 10.06 \\
Parking ramp & 172 & 0.56 \\
Access road & 3,794 & 12.33 \\
Available area for in-situ production & 19,824 & 64.43 \\
\hline
\end{tabular}

\subsection{Review Results and Discussions}

By examining the structure of heavy weight vehicle and production module based on the structural design of the upside of the underground structure of structure plan, it was confirmed to be safe. However, structural reinforcement through jack support and shore is required due to the need for usability3) in consideration of the vibration and impact caused by the frequent passage of construction equipments.

3) Usability means the performance of structure that satisfies the prevention of damage of finishing materials, retaining of original shapes of building, maintenance, pleasantness of occupants and functioning of machines in use by resisting the excessive lagging, unpleasant vibration, long-term deformation and crack.
After arranging the production equipment and construction equipment, about $44 \%$ free space remains on the upside of the underground structure. Since such free space provides the areas required for the execution of other works or stock of finishing materials, work can be executed as planned.

\section{Conclusion}

PC production in a PC plant not only causes the problems of delay in the construction period and damage during transportation, but also serves as a factor that increases the direct work cost compared to the cast-in-place method. However, in-situ production of PC may reduce risk and unit cost. Since there has been no study examining the insitu production of $\mathrm{PC}$, it is necessary to prove the feasibility by analyzing the influence factors for insitu production. In this regard, this study planned the in-situ production using the upside of an underground structure and analyzed the conditions. The following are the conclusions derived from this study.

First, influence factors were presented for planning the in-situ production. As well, it was shown that 8 influence factors presented here could be examined in terms of load and area conditions.

Second, the analysis and planning process of insitu production was presented. This process can also be utilized in the analysis of conditions for the application of in-situ production of composite PC members of Green Frame to other sites for the case study.

Third, the case projects were selected, conditions were examined in terms of load and area, confirming that in-situ production was possible.

As shown above, the results of this study proved 
that in-situ production of $\mathrm{PC}$ member of Green Frame could be realized in terms of load conditions and area conditions. The results of this study can be utilized as basic material for concretely planning the in-situ production plan of the PC member of Green Frame in the future.

\section{Acknowledgement}

This work was supported by the National Research Foundation of Korea (NRF) grant funded by the Korea government (MEST) (NO. 20110001031).

\section{References}

1. Lee SH, Kim SK, editors. A composite frame concept for the long life of apartment buildings. Proceedings of the 4th International Conference on Construction Engineering Project Management; 2011 February 16-18; Sydney, Australia. Sydney (Australia): University of New South Wales; 2011. p. 38.

2. Hong WK, Kim SK, Kim HG, Yoon TH, Yune DY, Kim SI. A Feasibility Study of Green Frame(GF) for the Implementation of Low-arbon Emissions \& Long-life Housing. Journal of the Korea Institute of Building Construction. 2010 February;10(1):57.

3. Kim SH, Kwon GD, Kim SK, Lee SH. Research on Improvement of PC Composite Frame. In: Lee KH, editors. Academic Conference of the Korea Institute of Ecological Architecture and Environment. 2010 Nov 18; Seoul, Korea. Seoul (Korea): Korea institute of Ecological Architecture and Environment; 2010. p. 65-6.

4. Korean Society of Architectural Hybrid System [PRECAST CONCRETE]. Seoul, Korea: Kimoondang; 2005. 261 p. Korean.

5. Kim SH. An Analysis of Economic Feasibility of Apartment Buildings Adopting PC Composite Rahmen Structure [master's thesis]. Yongin (Korea): Kyung Hee University; 2010. 87 p.

6. Rising of Environmentfriendly Apartment which has low Building-to-land Ratio[Internet]. Seoul:Segye.com. 2002-[cited 2011 May 10]. Available from: http://www.segye.com/.

7. Lee JM. Understanding of DB-Load. Journal of the Korean professional engineers association. 2009 Jan;42(1):44-8.

8. Ministry of Construction \& Transportation, [Road \& Bridge Standard Specification enacted by Ministry of Construction \& Transportation]. Seoul, Korea: Korea Road \& Transportation Association; 2005. 332 p. Korean. 